\title{
THE EPIDEMIOLOGY OF CONGENITAL ANOMALIES IN MULTIPLE BIRTHS: A EUROPEAN REGISTRY BASED STUDY
}

\author{
B.B. Boyle ${ }^{1}$, D. Helen ${ }^{2}$, R. McConkey ${ }^{2}$, EUROCAT Working Group \\ ${ }^{1}$ School of Nursing, ${ }^{2}$ University of Ulster, Newtownabbey, UK
}

The evidence that twins have a higher risk of congenital anomaly is strongest for monozygotic twins. The recent rise in the rate of multiple births, attributed to increases in maternal age and assisted reproductive therapies, is in dizygotic pairs; however, emerging evidence suggests an association between risk of congenital anomaly and reproductive therapies.

We report preliminary descriptive results from a study assessing the public health consequences of the rise in multiple births in terms of the risk of congenital anomaly.

Data from EUROCAT population based congenital anomaly registries in 14 European countries, representing over 6.7 million births 1984-2007 were analysed, including 163,000 congenital anomaly cases. Registry specific population births data for singleton and multiple deliveries were also obtained.

The proportion of multiple births in our study population rose from $1.9 \% 1984-88$ to $3.1 \% 2004-2008$. The relative risk of congenital anomaly in multiple births relative to singletons was RR 1.29 (95\% confidence interval, 1.25 to 1.32 ), with variations between anomaly types and between registries. The level of excess risk increased over time. Multiple pregnancies with congenital anomaly are less likely than singletons to result in termination, but more likely to result in stillbirth.

The rise in relative risk of congenital anomaly for multiple births may be due to additional risks of assisted reproduction or other causes. Survival outcomes differ from singleton affected babies and are relevant to assessing public health impact. 